\title{
CAFFEINE CONSUMPTION AMONG WORKERS WITH PSYCHO-EMOTIONAL RISK FACTORS
}

\author{
Teodora T. Dimitrova ${ }^{1}$, Darina N. Hristova ${ }^{2}$, Panayot N. Nikolov ${ }^{1}$ \\ 1) Department of Hygiene and Epidemiology, Faculty of Public Health, Medical \\ University of Varna, Bulgaria \\ 2) Department of Preclinical and clinical Sciences, Faculty of Pharmacy, \\ Medical University of Varna, Bulgaria.
}

\section{SUMMARY:}

Consumption of energy drinks grows worldwide which increases the need for research and scientific prove for their safe use concerning health effects they might cause among the population. Not properly discussed remains the issue about employers who offer their employees energy drinks in the workplace without any limits. Not fully clarified are the safe levels of consumption of caffeine by workers with a high level of mental tension.

Purpose is to explore coffee consumption among people working at different levels of stress in the workplace.

Material and methods: A cross-sectional study of coffee consumption and working conditions was conducted with an emphasis on psycho-emotional tension among working-age people from north-eastern Bulgaria. A structured proprietary questionnaire including questions about: coffee intake and working conditions has been developed.

Results: Daily consumption of coffee correlates with the following characteristics of the labor task:

- Level of stress according to self assessment 0,086

- Deficiency of time by performing daily obligations 0,121

- Risk of failure by daily tasks 0,208

- Presence of high work responsibility 0,143

Consumption of coffee among workers with high work responsibility is proven to lead to increased subjective feeling and fear of failures with serious consequences $(\mathrm{p}<0.05)$.

Conclusions: The complex approach for the evaluation of health effects caused by consumption of coffee includes the assessment of the risk factors due to working conditions and lifestyle.

Keywords: coffee, psycho-emotional tension, work

\section{INTRODUCTION:}

Consumption of energy drinks grows worldwide which increases the need for research and scientific prove for their safe use in regard to health effects they might cause among the population. Previous researches show a reliable increase in systolic blood pressure values for caffeine vs. decaffeinated drinks. However, differences in hypertensive responses within 1 hour after low-moderate consumption and high caffeine consumption have not been fully eluci- dated [1]. Disturbing the quality of sleep, caffeine over-consumption also indirectly affects mental health. Lack of healthy sleep itself exacerbates the risk of excessive consumption of tonic drinks by the person in order to overcome the fatigue that has occurred in the workplace. Fatigue that accumulates poses a risk of health consequences, and above all, in predominantly mental work these are the disturbances of mental health. Studies of the effects of caffeine on academic achievements among 7,377 young people indicate that daytime sleepiness can be associated with both alcohol and tobacco use and caffeine consumption. Consumption of coffee and energy drinks among young people is high. For example, according to a representative survey in Canada about $74 \%$ of the population,aged $12-24$ years use caffeinated beverages, and $16 \%$ exceed the safe daily dose (the maximum dose) [2]. In the last decade, the unfavorable combination of caffeine containing beverages (energy drinks) with alcohol has been permanently enforced which increases the risk of alcohol-related incidents. Apart from this caffeine consumption itself, mainly based on food imports through energy drinks is directly associated with some mental illness [3, 4]. At the same time, modern forms of work show a continuous tendency towards ever more widespread predominantly intellectual work. The psycho-emotional characteristics of workload are more and more proven occupational health risks. Stressful working conditions combined with prolonged working hours and an unhealthy lifestyle are the main factor for the epidemic of non-infectious diseases, including hypertension and metabolic disturbances. This requires preventive interventions and promotion of healthy nutrition at work in order to protect the public health and maintain working capacity. Not properly discussed remains the issue about employers who offer their employees energy drinks in the workplace without any limits. Not fully clarified are the safe levels of consumption of caffeine by workers with a high level of mental tension.

We set our goal to explore coffee consumption among people working at different levels of stress in the workplace.

\section{MATERIAL AND METHODS:}

A cross-sectional study of coffee consumption and working conditions was conducted with an emphasis on psycho-emotional tension among working-age people from 
north-eastern Bulgaria. 502 respondents were interviewed at the age of 19 to 80 . The average age of participants was $39 \pm 0.5$ years. They are divided into groups according to the level of self-assessment for psycho-emotional stress in the workplace.

Methods: A structured proprietary questionnaire including questions about: coffee intake and working conditions has been developed. The statistical processing was performed with the SPSS version 13 statistical package via descriptive, correlation and Hi-square analyzes. The significance level was set at values of $\mathrm{p}<0.05$ and $\mathrm{p}<0.01$

\section{RESULTS:}

The gender distribution of the surveyed contingent shows that men are 217 or $43.2 \%$ and women- 285 or $56.8 \%$. Coffee is a daily-consumed toning drink in the workplace with the majority of people working in psychoemotional stressors. (Figure 1)

Fig. 1. Daily use of coffee by workers exposed to psycho-emotional stressors (\%)

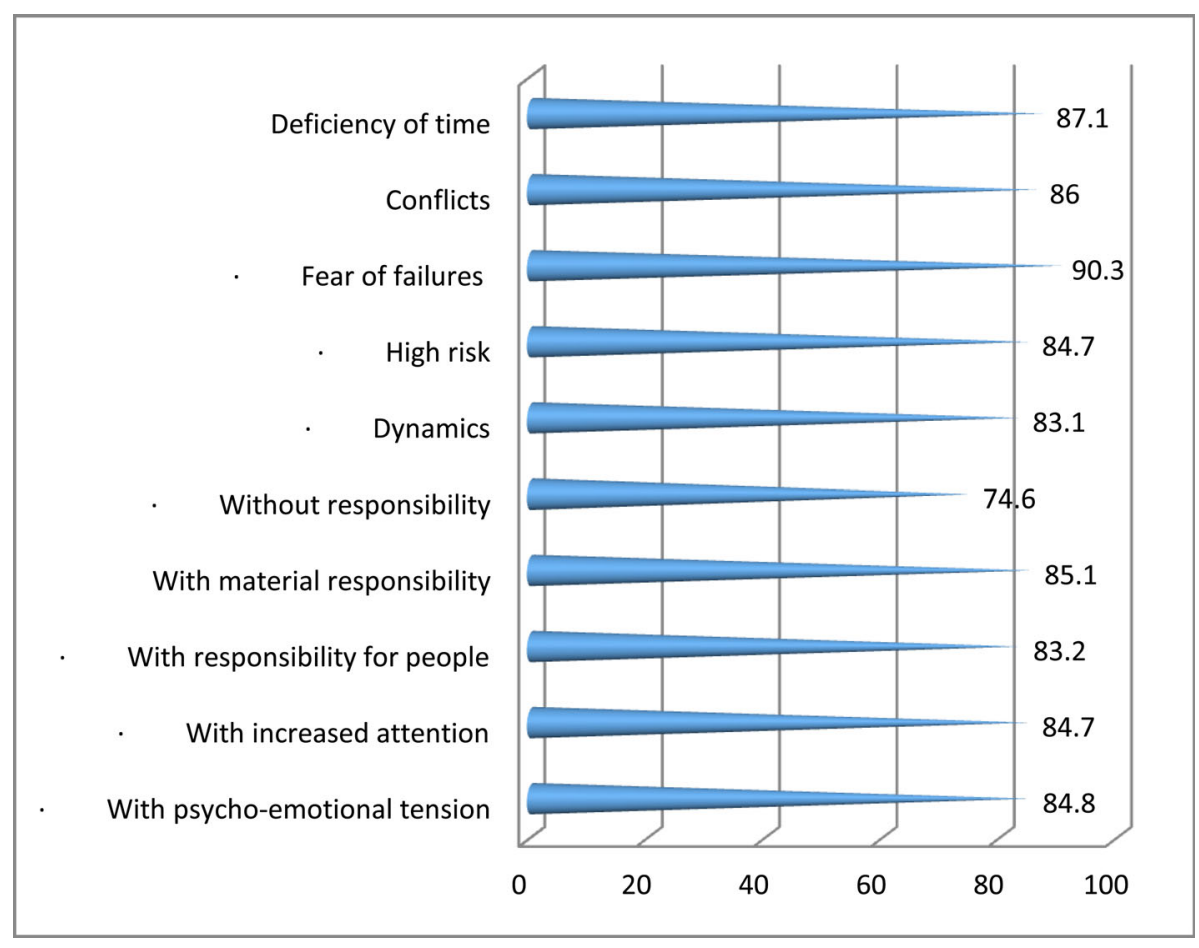

For a daily consumption of coffee report 40 people or $57,1 \%$ by people in hypostress, in addition to 130 or $65,3 \%$ in eustress up to 130 or $68,4 \%$ of people working in hyperstress .

Fig. 2. Distribution of daily coffee users according to the self-assessment of stress levels in the workplace (\%)

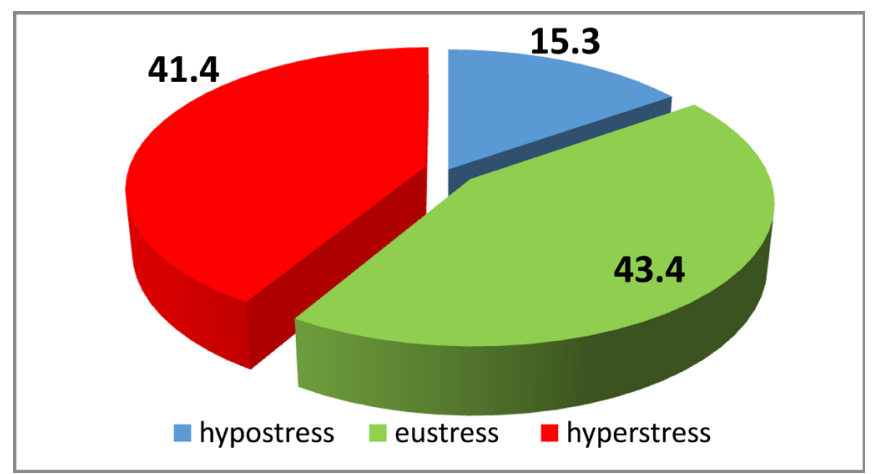

People who do not consume caffeine-conening drinks 7 or $14,9 \%$ of people with low levels of stress, in addition to 12 or $7,1 \%$ of people with moderate levels of stress and 16 or $10,3 \%$ fo respondents workin at high levels of stress according to their self-assessment. The reverse is the trend for the high consumption of more than three drinks a day, with the prevailing relative share of persons working in the conditions of hyperstress. (Figure 3 ) 
Fig. 3. Number of coffees per day according to the levels of stress

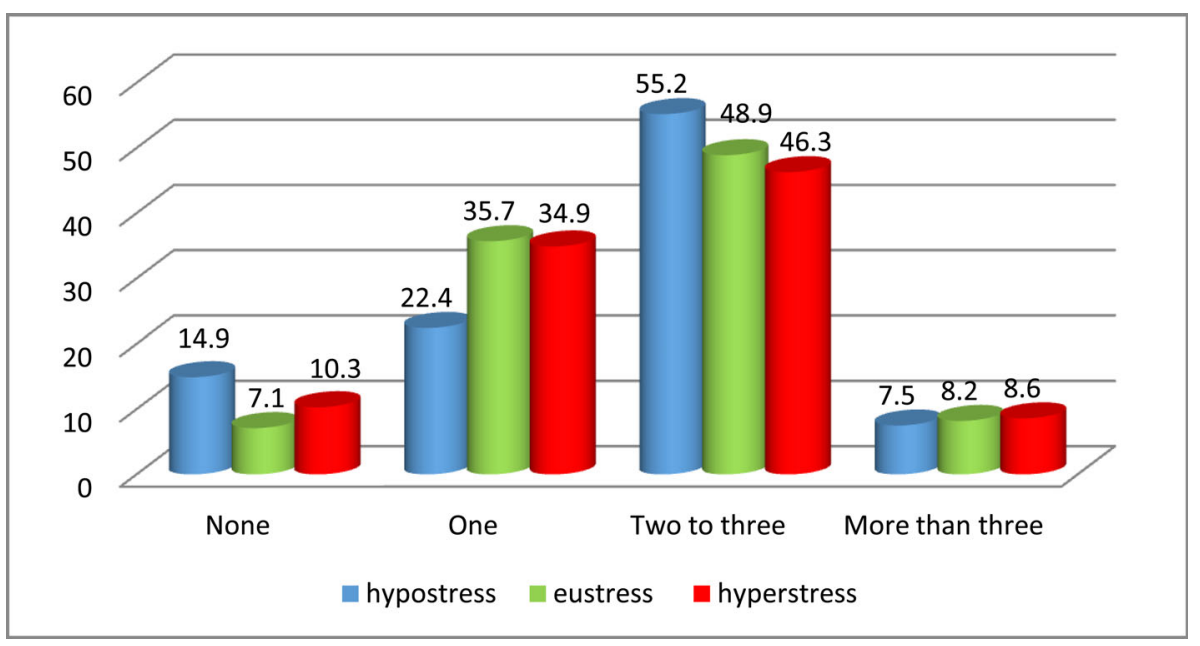

Daily consumption of coffee correlates with the following characteristics of the labor task:

- Level of stress according to self assessment 0,086

- Deficiency of time by performing daily obligations 0,121

- Risk of failure by daily tasks 0,208

- Presence of high work responsibility 0,143

There is no correlation between the number of coffees consumed daily by age and the level of stress in the workplace.

Consumption of coffee among workers with high work responsibility is proven to lead to increased subjective feeling and fear of failures with serious consequences $(\mathrm{p}<0.05)$.

\section{DISCUSSION}

The connection between stress at the workplace and caffeine consumption is hampered due to the significant interaction of caffeine with smoking [5]. A meta-analysis of three epidemiological studies found that almost $86 \%$ of smokers and only $77 \%$ of non-smokers consume coffee [6].

People who drink up to 3 coffees a day have a better memory and increased attention. The dementia processes slow down, and release of dopamine is triggered which reduces the risk of death due to Parkinson and lowers depressive syndromes.10- years research finds 0,85 ÎĐ by women, who consume 2-3 coffees daily [7].

Significant caffeine consumption, mainly by highenergy drinks, is associated with the incidence of mental illness, with no direct correlation [3] and depends on multiple factors. [4] Some studies indicate positive effects such as low caffeine doses that stimulate work capacity [8]. Evidence ,however, suggest dose-dependence of the responses, such as Kaplan et al. [9] found that $250 \mathrm{mg}$ increased mood, while $500 \mathrm{mg}$ lead to irritability. Acute immediate effects vary considerably depending on whether at the time of testing the participants in the study are in the period between consumption in the so-called caffeine deficiency or during attempts to reduce consumption. It is inappropriate to equate physiological reactions by non-consumers with those who are abstinent after several years of consumption [10].

Discussing the possibility that caffeinated beverages are likely to cause behavioral problems or might negatively affect mental health and work capacity, it is important to note that these products are often offered with an active marketing policy aimed at young people and inexperienced workers.

Young people aged between 12 and 17 represent the fastest growing population of caffeine consumers [11] as in $30-50 \%$ of cases they consume also energy drinks [3]. This once again proves the need to study the relationship between consumption of toning drinks in the workplace and mental health in regard to positive, negative and disputable effects.

A major searched effect of caffeine consumption is the immediate reduction of any signs of fatigue and improvement of performance [13, 14]. Double-blind studies comparing energy drinks versus placebo describe a correlation with increased activity, self-esteem, social extravertness [15], but also with depression and anxiety [16] and coping with fatigue in solving cognitive tasks [23]. Drinking caffeinated beverages shortens the reaction time for numerous visual and auditory stimuli, as well as monotonous tasks; improves the ability to analyze data, logical thinking, digital and verbal memory [17].

At the same time, Scholey and Kennedy [18], do not find any effects of drinks containing caffeine, glucose, ginseng or ginkgo biloba on the readiness for work. A study of Grasser et al. [19] publishes about a lack of differences in coping with stress between coffee consumers and water consumers who were given a task to deal with stressful mental arithmetic loads. Other studies have found evidence that caffeine can reduce cognitive impairment in conditions of chronic psychosocial stress, especially in unhealthy nutrition $[20,21]$.

Negative effects are mainly associated with an increase in tension and anxiety 1 hour after consumption [14]. Scientific literature mainly explores the positive immediate effects without taking into consideration any side effects. There are no studies on psychic effects by chronic use. From ten open-label studies on the influence of caffeinecontaining beverages on stress and stress-related conditions, 
two have not found a link, [22, 23], three describe one [24], and the rest have contradictory and indirect results due to lack of a direct correlation but with an established impairment of sleep quality [25, 26, 27]. Concerning anxiety levels, the results range from direct correlation with caffeine consumption [22, 28] to negative [29], as alcohol and smoking consumption are also obscuring factors. Conclusions of the studies investigating the association with depressive conditions are similar: a reduction in the symptoms [30, 24] to a worsening of the condition [31], and notably without reliably proven unilateral dependencies $[22,28]$.

\section{CONCLUSION}

Many studies on the possibility for an increase of the working capacity by acute effects of caffeine containing drinks have been made, but there is no clear evidence for health effects by prolonged use and over use. The evidence for a connection between energy drinks and psychic disorders is increasing.

More research is needed in regard to safe consumption of coffee as toning drink in the working place among employees with high level of stress also in regard to combined negative health effects on the cardio-vascular system, metabolism and psychics.

The complex approach for the evaluation of health effects caused by consumption of coffee includes the assessment of the risk factors due to working conditions and lifestyle.

\section{REFERENCES:}

1. Cheung M, Quach J, Chan A, Nguyen NN, Shah SA. Effects of Energy Shots on Blood Pressure in Caffeine-Naive Versus Caffeine-Consuming Healthy Volunteers. J Caffeine Res. 2016 Dec;6(4)148-153. [Crossref]

2. Reid JL, McCrory C, White CM, Martineau C, Vanderkooy P, Fenton N, et al. Consumption of Caffeinated Energy Drinks Among Youth and Young Adults in Canada. Prev Med Rep. 2016 Nov 14;5:65-70. eCollection 2017 Mar. [PubMed] [Crossref]

3. Kendler KS, Myers J, Gardner CO. Caffeine intake, toxicity and dependence and lifetime risk for psychiatric and substance use disorders: An epidemiologic and co-twin control analysis. Psychol Med. 2006 Dec; 36(12):1717-25. [PubMed] [Crossref]

4. Lara DR. Caffeine, mental health, and psychiatric disorders. $J$ Alzheimers Dis. 2010; 20 Suppl 1: S239-248. [PubMed] [CrossRef]

5. Conway TL, Vickers RR Jr, Ward HW, Rahe RH. Occupational stress and variation in cigarette, coffee, and alcohol consumption. J Health Soc Behav. 1981 Jun;22(2):155-65. [PubMed]

6. Swanson J, Lee JW, Hopp JW. Caffeine and nicotine: a review of their joint use and possible interactive effects in tobacco withdrawal. Addict behav, 1994 May-Jun;19(3):229-56. [PubMed]

7. Pham N, Nanri A, Kurotani K, Kuwahara K, Kume A, Sato M, et al. Green tea and coffee consumption is inversely associated with depressive symptoms in a Japanese working population. Public Health Nutr. 2014 Mar;
17 (3): 625-33. [PubMed]

8. Haskell CF, Kennedy DO, Wesnes KA, Scholey AB. Cognitive and mood improvements of caffeine in habitual consumers and habitual non-consumers of caffeine. Psychopharmacology (Berl). 2005 Jun;179(4):813-25. [PubMed]

9. Kaplan GB, Greenblatt DJ, Ehrenberg BL, Goddard JE, Cotreau MM, Harmatz JS, et al. Dose-dependent pharmacokinetics and psychomotor effects of caffeine in humans. $J$ Clin Pharmacol. 1997 Aug;37(8):693703. [PubMed]

10. Gilliland K, Andress D. Ad-lib caffeine consumption, symptoms of caffeinism, and academic performance. Am J Psychiatry. 1981 Apr;138(4):5124. [PubMed]

11. Seifert SM, Schaechter JL, Hershorin ER, Lipschultz SE. Health effects of energy drinks on children, adolescents, and young adults. Pediatrics. 2011 Mar;127(3):511-28. [PubMed]

12. Frary CD, Johnson RK, Wang MQ. Food sources and intakes of caffeine in the diets of persons in the United States. J Am Diet Assoc. 2005 Jan;105(1):110-3. [PubMed]

13. Salinero JJ, Lara B, AbianVicen J, Gonzalez-Millán C, Areces F, Gallo-Salazar C, et al. The use of energy drinks in sport: perceived ergogenicity and side effects in male and female athletes. Br J Nutr. 2014 Nov 14; 112(9):1494-502. [PubMed] [Crossref]

14. Sünram-Lea SI, Owen-Lynch J, Robinson SJ, Jones E, Hu H. The effect of energy drinks on cortisol lev- els, cognition and mood during a firefighting exercise. Psychopharmacology (Berl). 2012 Jan;219:83-97. [PubMed]

15. Seidl R, Peyrl A, Nicham R, Hauser E., A taurine and caffeine-containing drink stimulates cognitive performance and well-being. Amino Acids. 2000;19(3-4):635-42. [PubMed]

16. Yudko E, McNiece SI. Relationship between coffee use and depression and anxiety in a population of adult polysubstance abusers. $J$ Addict Med. 2014 Nov-Dec; 8(6):438-42. [PubMed]

17. Ullrich S, de Vries YC, Kühn S, Repantis D, Dresler M, Ohla K .Feeling smart: Effects of caffeine and glucose on cognition, mood and self-judgment. Physiology \& Behav.2015 Nov 1; 151: 629-637. [PubMed]

18. Scholey AB, Kennedy DO. Cognitive and physiological effects on an "energy drink": An evaluation of the whole drink and of glucose, caffeine and herbal flavouring fractions. Psychopharmacology (Berl). 2004 Nov;176(3-4):320-330. [PubMed]

19. Grasser EK, Dulloo AG, Montani JP, Cardiovascular and cerebrovascular effects in response to red bull consumption combined with mental stress. Am J Cardiol. 2015 Jan 15; 115(2):183-9. [PubMed]

20. Alzoubi KH, Abdul-Razzak KK, Khabour OF, Al-Tuweiq GM, Alzubi MA, Alkadhi KA. Caffeine prevents cognitive impairment induced by chronic psychosocial stress and/or high fat-high carbohydrate diet. Behav Brain Res. 2013 Jan 15;237:7- 


\section{4. [ubMed] [ $\underline{\text { Crossref }}$}

21.Kasimay Cakir O, Ellek N, Salehin N, Hamamcý R, Kelep H, Kayalý DGet al. Protective effect of low dose caffeine on psychological stress and cognitive function. Physiol Behav. 2017 Jan 1; 168:1. [PubMed]

22. Richards G, Smith A. Caffeine consumption and self-assessed stress, anxiety, and depression in secondary school children. J Psychopharmacol. 2015 Dec;29(12):1236-1247. [PubMed]

23. Ríos JL, Betancourt J, Pagán I, Fabian C, Cruz SY, Gonzales MJ. Caffeinated-beverage consumption and its association with socio-demographic characteristics and self-perceived academic stress in first and second year students at the University of Puerto Rico Medical Sciences Campus (UPR-MSC). P R Health Sci J. 2013 Jun;32(2):95-100. [PubMed]

24. Trapp G, AllenK, O’Sullivan
TA, Robinson M, Jacoby P, Oddy WH. Energy drink consumption is associated with anxiety in Australian young adult males. Depress Anxiety. 2014 May;31(5):420-8. [PubMed]

25. Peters RJ Jr, Meshack A, Amos C, Scott-Gurnell K, Savage C, Ford K. The association of drug use and posttraumatic stress reactions due to Hurricane Ike among Fifth Ward Houstonian youth. J Ethn Subst Abuse. 2010; 9(2):143-51. [PubMed] [Crossref]

26. Vilija M, Romualdas M. Unhealthy food in relation to posttraumatic stress symptoms among adolescents. Appetite. 2014 Mar;74:86-91. [PubMed]

27. Waits WM, Ganz MB, Schillreff T, Dell PJ. Sleep and the use of energy products in a combat environment. US Army Med Dep J. 2014 Oct-Dec:22-8. [PubMed]

28. Yudko E, McNiece SI. Relationship between coffee use and de- pression and anxiety in a population of adult polysubstance abusers. $J$ Addict Med. 2014 Nov-Dec;8(6):438-442. [PubMed]

29. Snipes DJ, Jeffers AJ, Green BA, Benotsch EG. Alcohol mixed with energy drinks are robustly associated with patterns of problematic alcohol consumption among young adult college students. Addict Behav. 2015 Feb; 41:136-41. [PubMed]

30. Evren C, Evren B. Energydrink consumption and its relationship with substance use and sensation seeking among 10th grade students in Istanbul. Asian J Psychiatr. 2015 Jun; 15:44-50. [PubMed]

31. Azagba S, Langille D, Asbridge M. An emerging adolescent health risk: Caffeinated energy drink consumption patterns among high school students. Prev Med. 2014 May; 62:549. [PubMed] [Crossref]

Please cite this article as: Dimitrova TT, Hristova DN, Nikolov PN. Caffeine Consumption among Workers with Psycho-Emotional Risk Factors. J of IMAB. 2018 Oct-Dec;24(4):2285-2289.

DOI: https://doi.org/10.5272/jimab.2018244.2285

Address for correspondence:

Teodora Todorova Dimitrova,

Department of Hygiene and Epidemiology, Faculty of Public Health, Medical University of Varna

55, Marin Drinov Str., 9000, Varna, Bulgaria.

E-mail: t.dimitrova@mu-varna.bg 